\title{
Lymphocyte recognition of human parvovirus B19 non-structural (NS1) protein: associations with occurrence of acute and chronic arthropathy?
}

\author{
LESLIE ANN MITCHELL, ROGER LEONG, and KARLA A. ROSENKE
}

Department of Pathology, University of British Columbia, BC Research Institute for Children's and Women's Health, 950 West 28th Avenue, Vancouver, BC V5Z 4H4, Canada

\begin{abstract}
Immune recognition of recombinant parvovirus B19 non-structural (rNS1) protein was studied by immunoblot and lymphoproliferative assays in blood from the following B19 seropositive groups: B19 infected $(n=14), B 19$ exposed but non-infected $(n=16)$, other illness with rash $(n=3)$, chronic arthropathy of unknown aetiology $(n=4)$ and healthy controls $(n=7)$. Sera from 11 B19 seronegative subjects were also studied. Sera collected at initial diagnosis or at the time of accidental B19 exposure in pregnancy were tested for NS1 antibody and evidence of B19 DNA by nested PCR. Follow-up specimens were obtained 3-12 months later for serological, PCR and proliferation studies. B19 DNA was detected sporadically in early specimens and in one follow-up specimen from a subject who developed chronic arthropathy after B19 infection. There was no correlation with development of arthropathy. NS1-specific IgG was detected in early sera from B19infected and exposed subjects but to a lesser degree in follow-up specimens, and in only one healthy control serum. No correlation with the presence of NS1-specific antibodies was found with development of acute or chronic arthropathy. Although lymphocyte proliferation in response to stimulation with rNS1 in vitro occurred at a higher frequency in patients who developed acute and chronic joint manifestations after B19 infection, suggesting an association with this outcome, NS1-reactive lymphocytes were also found in three $B 19$ seronegative patients, two of whom had recently been exposed to B19 but had no illness. Hence, immune recognition of NS1 may be more indicative of recent infection with, or exposure to, parvovirus B19 than associated with development of arthropathy as previously reported.
\end{abstract}

\section{Introduction}

Infections with human parvovirus B19 are common in children and adults who have not acquired immunity to B19 earlier. In most cases, B19 disease (erythema infectiosum, EI, or fifth disease) is mild, self-limited and characterised by facial rash progressing to a maculopapular rash on the trunk and limbs accompanied by 'flu'-like symptoms [1]. The disease is very contagious and seroconversion studies suggest that the asymptomatic infection rate for household, daycare and school contacts of EI cases is between 25 and $60 \%$

Received 15 Feb. 2000; revised version received 12 Oct. 2000; accepted 5 Nov. 2000.

Corresponding author: Dr L.A. Jonsen (Mitchell). Present address: Goldyne Savad Institute of Gene Therapy, Hadessah Hospital, P.O.B. 12000 Jerusalem 91120, Israel.
$[2,3]$. Approximately $50 \%$ of adult EI cases are associated with acute joint manifestations (arthropathy) lasting 1-4 weeks $[1,2,4]$. These range from pain only (arthralgia) to arthritis (pain with swelling, redness and loss of function) and are usually symmetrical, affecting mainly the small joints of the hands and feet. Women appear to be more susceptible to B19 infection-related arthropathy than men or children, and of those afflicted, c. $20 \%$ experience persistent or recurrent joint symptoms for months to years [1]. About $50 \%$ of these cases resemble seronegative rheumatoid arthritis (RA) and several studies have linked evidence of earlier B19 infection with adult RA and juvenile rheumatoid arthritis (JRA) [4-7], whereas other studies have found weaker or no associations [8-10]. The case for B19 involvement in chronic arthritis has been based on evidence of viral persistence in the bone marrow, peripheral blood and synovial tissues as determined by PCR, as well as the continued presence of B19-specific $\operatorname{IgM}$ in sera of such patients $[5,11-16]$. However, other 
studies showed that B19 may persist in synovial membranes without causing joint manifestations [17].

The parvovirus B19 DNA genome encodes two capsid proteins (VP1 and VP2) which contain domains responsible for viral entry into host cells and, hence, are sites to which neutralising antibodies are directed [1]. Also encoded are two non-structural proteins, NS1 and NS2 [18]. Although the role of NS2 is presently unknown, NS1 functions as a helicase, DNA-nickase and transactivator of the viral promoter (P6) in viral replication [18]. Overexpression of NS1 in nonpermissive cell lines leads inevitably to cell cycle arrest and cell death $[18,19]$. Antibodies that recognise recombinant NS1 (rNS1) have been demonstrated in sera from persistently B19-infected individuals [20]. NS1-specific antibodies have also been found in sera from patients with chronic arthritis resulting from earlier confirmed B19 infection, but not in sera from healthy B19 seropositive individuals [21].

Although neutralising antibodies directed to domains on VP1 and VP2 are considered to play an important role in viral clearance [1], systemic cellular responses can be measured in peripheral blood $[22,23]$ in individuals with and without joint complications. von Poblotzki et al. [24] demonstrated lymphocyte proliferative responses to recombinant (r) VP1 and VP2 proteins (but rarely to rNS1) in healthy B19 seropositive individuals. In this study, lymphocytes capable of proliferating in vitro in response to rNS1 stimulation were detected in peripheral blood taken from individuals 8-11 months after documented B19 infection. Results suggest, but do not confirm, an association of lymphocyte reactivity to rNS1 with occurrence of acute and chronic arthropathy. As it is difficult to study parvovirus B19 infections prospectively because of delays in clinical and serological diagnosis, this study was designed to examine, retrospectively, aspects of the B19 immune response in relation to clinical outcome and evidence of virus persistence (i.e., NS1-specific IgG and presence of B19 genomic sequence in peripheral blood).

\section{Materials and methods}

\section{Study subjects and samples}

Study subjects were 55 adults (45 females, 10 males) who had previously been tested for parvovirus B19specific IgM or IgG antibodies, or both, by a commercial enzyme immunoassay (EIA) which uses recombinant baculovirus-expressed B19 VP2 antigen to detect specific antibodies (Biotrin International, Mount Merrion, Eire). The majority of the study subjects $(n=43)$ were identified through parvovirus B19 antibody testing rosters provided by the Virology Laboratory at the BC Centre for Disease Control (BCCDC, Vancouver, Canada). These subjects had been referred for B19 antibody testing by their attending physicians for the purpose of diagnosing exanthematous or rheumatological illness or to confirm B19 serological status in the case of accidental exposure to EI in pregnancy. The remaining subjects $(n=12)$ were healthy volunteers who were also tested for B19specific IgG antibody by the same method. After informed consent, as required by the University of British Columbia Ethics Committee, detailed clinical histories were obtained from each study subject including: the circumstances preceding the original request for B19 serology; clinical evidence of EI (rash; fever; 'flu'-like illness; incidence, type, location and duration of joint manifestations, and other complications); history of past joint manifestations; personal or family history of connective tissue or other autoimmune disease; current medications and pregnancy status. In the case of patient study volunteers, original serum specimens used at initial diagnosis were retrieved from the BCCDC frozen specimen archives and taken to this laboratory for further testing by immunoblot assays and B19-specific PCR (see below). Follow-up blood specimens, including heparinised, EDTA and clotted blood, were collected for lymphocyte proliferation assays, PCR detection of B19 DNA and immunoblot assays, respectively. In subjects confirmed serologically (by presence of B19-specific $\operatorname{IgM})$ to have been infected recently (i.e., within 12 months) with B19 or exposed (without ensuing illness) to a confirmed case of B19 disease, follow-up samples were collected within a relatively narrow time frame (8-12 months) after disease onset or exposure. As the actual time of B19 infection and initial seroconversion were unknown in the remaining groups, follow-up samples represent a second examination of the remote convalescent immune response and the frequency of B19 viral persistence in such individuals. After informed consent and clinical history documentation, blood specimens (as above) were also obtained from healthy controls and samples of serum were sent to the BCCDC for determination of B19 serological status by the Biotrin EIA.

\section{Parvovirus B19 recombinant non-structural (rNS1) protein and rabbit anti-NS1 serum}

Recombinant parvovirus B19 NS1 protein (rNS1) and rabbit anti-NS1 antiserum were gifts of Dr Caroline Astell (Department of Biochemistry \& Molecular Biology, University of British Columbia, Canada). rNS1 was prepared in the laboratory of Dr Astell by cloning a fusion protein comprised of (His) ${ }_{6}-\mathrm{NS} 1$, by PCR, into the expression plasmid, pQE40 (unpublished results). This fusion protein was expressed in Escherichia coli cells, then solubilised with $6 \mathrm{M}$ guanidine $\mathrm{HCl}$ and purified on $\mathrm{Ni}^{+}$-Sepharose column (Invitrogen, San Diego, CA, USA) in the presence of $8 \mathrm{M}$ urea. The purified protein was renatured by dialysis against a buffer containing NP-40 1\%, $50 \mathrm{mM}$ Tris, $150 \mathrm{mM}$ $\mathrm{NaCl}$ ( $\mathrm{pH}$ 7.9). rNS1 was characterised by immunoblotting with a rabbit anti-NS1 serum (A13RD) raised 
by immunising rabbits with a synthetic peptide representing a C-terminal sequence of B19 NS1 protein [25].

Antibody testing. Parvovirus B19-specific IgM and IgG antibodies were determined by the Biotrin EIA (as described above) according to the manufacturer's directions, at the BCCDC. Results were expressed non-quantitatively as either 'reactive' or 'non-reactive'. NS1-specific IgG antibodies were measured by reducing immunoblot assays by standard protocols. To remove antibodies which might react with E. coli antigens potentially remaining in the rNS1 preparation, patient sera were pre-absorbed by incubating with a lysate of $E$. coli $\mathrm{K} 512$ cells for $4 \mathrm{~h}$ at room temperature, then cleared by centrifugation at $10000 \mathrm{rpm}$ for $10 \mathrm{~min}$ before testing in immunoblot assays. The efficacy of this pre-treatment was verified by testing adsorbed sera by immunoblotting against E. coli lysate. rNS1 at a concentration of $2 \mu \mathrm{g} / \mathrm{ml}$ (total volume of $68 \mu \mathrm{l})$ was loaded into a single long well with a large slot comb and subjected to SDS-PAGE on mini-gels which were subsequently blotted on to nitrocellulose. The nitrocellulose blot was blocked in skimmed milk $4 \%$ in Tris-buffered saline (TBS, $\mathrm{pH} 7.4$ ) and cut into $0.5-\mathrm{cm}$ strips which were then incubated overnight with individual patient sera or positive control (rabbit antiNS1) serum at a 1 in 25 dilution (previously shown to be optimal) in blocking buffer in $12 \times 75 \mathrm{~mm}$ capped tubes with constant shaking. Negative controls included pre-immunisation serum from the same rabbit and serum from a single human donor shown to be consistently negative in both the Biotrin EIA and NS1 immunoblot assays. The blots were then washed on a shaker for $30 \mathrm{~min}$ in TBS containing Tween-20 $0.05 \%$ (washing buffer). After this, the strips were incubated for $2 \mathrm{~h}$ at room temperature in a 1 in 500 dilution of alkaline phosphatase-conjugated affinity purified goat anti-human IgG (in the case of patient sera) or alkaline phosphatase-labelled mouse anti-rabbit IgG (in the case of positive control strips) (both obtained from Kirkegaard \& Perry Laboratories, Gaithersburg, MD, USA). At the end of the incubation, the conjugate solutions were discarded and the blotted strips were washed as before. To detect antibodies bound specifically to rNS1, BCIP/NBT substrate (5bromo-4-chloroindolyl phosphate/nitroblue tetrazolium in Tris- $\mathrm{Mg}^{2+}$ buffer, $\mathrm{pH}$ 9.5) was added to the tubes containing the blotted strips and these were incubated at room temperature with shaking until specific bands (see Results) appeared on the positive control and positive patient serum specimens (c. $30 \mathrm{~min}$ ). The strips were rinsed with distilled $\mathrm{H}_{2} \mathrm{O}$, allowed to dry in air, then interpreted independently by two investigators (L.A.M. and R.L.) for concordance of results.

\section{PCR detection of parvovirus B19 DNA sequences present in patient serum}

Parvovirus B19 DNA sequences present in original sera (retrieved from the BCCDC archives) and follow-up serum specimens were detected by nested PCR. Primer pairs used for amplification (Table 1) were designed from a description of RNA transcripts found to be abundant in permissive cell lines infected with parvovirus B19 [11]. Primer sequences (shown in Table 1) represent those reported by Shade et al. [25]. Primers PAR-A and PAR-B were used in first stage amplifications of $2 \mu \mathrm{g}$ of DNA for each reaction which was heat-denatured at $95^{\circ} \mathrm{C}$ for 2 min then subjected to amplification in the presence of unlabelled dNTPs (Boehringer-Mannheim, Laval, Quebec, Canada) and Taq polymerase (Bio/Can, Mississauga, ON, Canada) with 25 cycles alternating $94^{\circ} \mathrm{C}$ for $30 \mathrm{~s}$ and $45^{\circ} \mathrm{C}$ for $1 \mathrm{~min}$. Second stage amplifications with the PAR-1/ PAR-2 primer pair were performed by adding one more unit of Taq polymerase to the tube containing the first amplification materials, then performing 25 cycles at $94^{\circ} \mathrm{C}(30 \mathrm{~s})$ and $6^{\circ} \mathrm{C}(1 \mathrm{~min})$. Positive controls consisted of an acute serum specimen obtained from a patient with serologically confirmed B19 infection which was included in each set of PCR reactions, and a plasmid construct (pSVOd $\Delta 170$ ) containing $c .5000 \mathrm{bp}$ of parvovirus B19 DNA (also provided by Dr C. Astell). PCR products were electrophoresed on agarose-ethidium bromide gels which were then photographed under UV light to identify the specific PCR band (c. 192 NBP) relative to that present in the positive control. Sensitivity of the PCR was estimated to be $c$. $3 \mathrm{fg}$ with the above plasmid construct.

\section{Lymphocyte proliferation assays}

Peripheral blood mononuclear cells were isolated from heparinised blood by density gradient centrifugation with Ficoll-Hypaque, washed by centrifugation through RPMI-1640 medium (Canadian Life Technologies, Mississauga, ON, Canada), resuspended in OptiMEM medium (Canadian Life Technologies) supplemented with penicillin $\left(10^{5} \mathrm{U} / \mathrm{L}\right)$, streptomycin $(100 \mathrm{mg} / \mathrm{L})$ and 2-mercaptoethanol $\left(2 \times 10^{-5} \mathrm{M}\right)$, then cultured at an initial density of 100000 cells/well in 96-well

Table 1. Parvovirus B19-specific primer sequences for nested PCR

\begin{tabular}{ll}
\hline Primers & Sequence \\
\hline PAR-A (2312-2297) & 5'- TTA TAC CAA GCC CCT A -3' \\
PAR-B (2077-2092) & 5'- ACC AGT TCA GGA GAA T -3' \\
PAR-1 (2286-2263) & 5'- ATG GGG ACA AAG TCC CAA CCC TCC -3' \\
PAR-2 (2095-2115) & 5'- TTT GTC GGA AGC CCA GTT TCC TCC -3' \\
\hline
\end{tabular}


microculture plates in the presence of rNS1 and $2 \mathrm{mg} / \mathrm{L}$ autologous plasma $10 \%$ (final concentration) for 7 days at $37^{\circ} \mathrm{C}$, in $\mathrm{CO}_{2} 5 \%$ in air, by established procedures [26]. Control wells received medium and autologous plasma only (negative) or phytohaemagglutinin (PHA, $2 \mathrm{mg} / \mathrm{L}$ final concentration). Wells containing PHA were examined with an inverted microscope on day 3 of the culture to verify that cells were dividing. At the end of the 7-day incubation period, the extent of cell division was determined by adding ${ }^{3} \mathrm{H}$-thymidine (Amersham, Oakville, ON, Canada) $2 \mu \mathrm{Ci} /$ well during the last $6 \mathrm{~h}$ of culture. DNA from cells was harvested and counted for incorporated radioactivity. Results were expressed as a stimulation index (SI) computed as described previously [26]. SIs $>2$ were considered indicative of a positive response to the stimulating antigen.

\section{Data analysis}

Proportional differences in recognition of rNS1 (SI $>2.0)$ by lymphocytes from patient study groups (see Results) were determined by calculation of Zscores and interpretation of $\mathrm{p}$ values from standard tables; $p$ values $<0.05$ were considered to be significant.

\section{Results}

\section{Study subjects, clinical findings and serological status}

For data analysis, study subjects were allocated to groups according to their initial B19 serological (as determined by the Biotrin EIA) and clinical status. Table 2 shows results for B19 (VP2) seropositive subjects. The first group of subjects shown in Table 2 were those who had experienced EI confirmed clinically or serologically, or both. These included seven patients who had experienced acute joint manifestations (arthralgia and arthritis) lasting 1-4 weeks after onset of EI signs, and seven patients who had continued to experience polyarthralgias or arthritis, or both, lasting longer than 4 weeks. Four of these latter individuals had persistent joint manifestations at the time of follow-up, and one (subject 142) had experienced five episodes of rash and joint pain and stiffening for a period of at least 12 months after initial B19 infection. This patient was well at the time of follow-up (18 months after the initial episode) and in her seventh month of an uncomplicated pregnancy. All but five of these patients were confirmed to have B19 infection on the basis of B19 capsid-specific IgM (as determined by the Biotrin EIA detecting antibodies directed to VP2; Table 2) in their acute serum as well as the presence of clinical signs (fever, rash, joint manifestations). Patients $142,180,122,126$ and 134 were not tested for VP2-specific IgM during the acute phase of their illness, but had presented with two or more clinical signs of B19 disease (as documented above) and reported exposure to a known case of fifth disease shortly before their illness. All individuals in this group had B19 capsid-specific IgG in their initial and followup specimens and two subjects (149 and 172) had persistent IgM at 9.5 and 7.5 months, respectively, after onset of EI. For most patients in this group, initial specimens (obtained from BCCDC archives) had been collected 1-21 days after onset of symptoms. Followup specimens were collected for PCR, antibody and lymphoproliferation testing at 7.5-12 months after the estimated time of B19 disease onset.

A second group of subjects comprised three B19 VP2 IgG-positive subjects with a history of other rash illness. Two (subjects 186 and 125) had experienced a rash thought to be a reaction to sulphonamide or other drugs. The third subject (095) had been diagnosed with measles (serologically confirmed by detection of measles-specific IgM) and had experienced acute and recurrent arthralgias. None of these patients had serum B19 capsid-specific IgM at the time of initial investigation of during follow-up.

A third group of study subjects (Table 2) comprised four VP2 IgG-positive subjects undergoing rheumatologic assessment for chronic arthropathy of unknown aetiology. All patients in this category were found to be negative for B19 capsid-specific IgM.

A fourth group comprised 16 VP2-specific IgG-positive women who had been exposed to a known case of fifth disease in pregnancy ('B19 exposure'; Table 2). They had all been tested initially within 3 weeks of exposure to B19. All had been evaluated for presence of VP2specific $\operatorname{IgM}$ in their serum at the time of exposure and were found to be negative. None had experienced any signs of EI, including joint manifestations, and there were no apparent adverse effects on the pregnancy that were related to B19 exposure. Frozen serum samples from the original tests for B19 antibodies were retrieved from BCCDC archives. Follow-up specimens were collected for PCR, antibody and lymphoproliferation studies 8-11 months after exposure to B19. None of the women was pregnant at the time of follow-up.

The last group shown in Table 2 comprised seven VP2 IgG-positive healthy controls who were recruited from laboratory staff at this research institute. None reported recent illness suggestive of B19 disease and, hence, it was assumed that they were seropositive as a result of earlier undocumented B19 infection. None of the healthy controls had a history of joint or connective tissue disease.

Table 3 shows data for B19 VP2 IgG- and IgMnegative study subjects including two patients with chronic arthropathy (183, recurrent polyarthralgia; 174 , onset of arthralgia and arthritis affecting hands and feet following a bacterial abscess on the coccyx), four women who had been exposed to an EI case in 
Table 2. Immune response to NS1 in relation to occurrence of joint manifestations and presence of B19 DNA in serum of B19 seropositive subjects

\begin{tabular}{|c|c|c|c|c|c|c|c|c|c|c|}
\hline \multirow{2}{*}{$\begin{array}{l}\text { Study } \\
\text { no. }\end{array}$} & \multirow{2}{*}{$\begin{array}{l}\text { Sex, age } \\
\text { (years) }\end{array}$} & \multicolumn{2}{|c|}{ Arthropathy* } & \multicolumn{3}{|c|}{ Sample 1} & \multicolumn{3}{|c|}{ Sample 2} & \multirow[b]{2}{*}{$\mathrm{NS} 1 \mathrm{SI}^{\dagger}$} \\
\hline & & Acute & Recurrent & Time & PCR & NS1 bands* & Time & PCR & NS1 bands* & \\
\hline \multicolumn{11}{|c|}{ B19 infected } \\
\hline 143 & f, 32 & $\mathrm{a}, \mathrm{A}$ & none & 7 days & + & 7 & 10 months & - & 7 & 0.3 \\
\hline 153 & $\mathrm{f}, 34$ & $\mathrm{a}, \mathrm{A}$ & $\mathrm{a}$ & 75 days & - & 7 & 10 months & - & none & 4.4 \\
\hline 157 & $\mathrm{~m}, 48$ & $\mathrm{a}, \mathrm{A}$ & $\mathrm{a}, \mathrm{A}$ & 3 days & - & 7 & 10 months & - & $1-3,7$ & 4.8 \\
\hline 149 & f, 36 & $\mathrm{a}, \mathrm{A}$ & $\mathrm{a}, \mathrm{A}$ & 3 days & - & 7 & 9.5 months & + & 7 & 4.3 \\
\hline 137 & $\mathrm{f}, 40$ & $\mathrm{a}, \mathrm{A}$ & none & 30 days & - & $1-3,6,7$ & 11 months & - & $1-3,6,7$ & 2.3 \\
\hline 175 & $\mathrm{f}, 31$ & $\mathrm{a}, \mathrm{A}$ & none & 17 days & + & $1-3,7$ & 9 months & - & none & 13.5 \\
\hline 165 & $\mathrm{f}, 28$ & a & none & 18 days & + & $1-3,7$ & 8 months & - & $1-3,4,7$ & 0.4 \\
\hline 172 & $\mathrm{f}, 44$ & $\mathrm{a}, \mathrm{A}$ & none & 6 days & + & none & 7.5 months & - & $1-3,7$ & 2.7 \\
\hline 160 & $\mathrm{f}, 34$ & $\mathrm{a}, \mathrm{A}$ & $\mathrm{a}$ & 1 day & - & $1-3$ & 11 months & - & none & 0.3 \\
\hline 142 & $\mathrm{f}, 25$ & $\mathrm{a}, \mathrm{A}$ & $\mathrm{a}, \mathrm{A}$ & 12 months & - & $1-3,4,7$ & 20 months & - & none & 0.9 \\
\hline 180 & $\mathrm{~m}, 35$ & $\mathrm{a}, \mathrm{A}$ & none & ND & ND & ND & 7.5 months & - & none & 4.5 \\
\hline 122 & $\mathrm{f}, 34$ & $\mathrm{a}, \mathrm{A}$ & none & 21 days & - & none & 12 months & - & $1-3,6$ & 0.6 \\
\hline 126 & f, 46 & $\mathrm{a}, \mathrm{A}$ & $\mathrm{a}$ & 1 day & - & $1-3,4$ & 10 months & - & $1-3$ & 3.7 \\
\hline 134 & $\mathrm{f}, 35$ & $\mathrm{a}, \mathrm{A}$ & $\mathrm{a}, \mathrm{A}$ & 2 days & - & none & 11 months & - & none & 0.7 \\
\hline \multicolumn{11}{|c|}{ Other illness with rash } \\
\hline 186 & $\mathrm{f}, 38$ & none & none & 5 days & - & 4,6 & 3 months & - & none & 0.9 \\
\hline 125 & f, 57 & none & none & 1 day & - & $1-3,7$ & 7 months & - & none & 0.6 \\
\hline 095 & $\mathrm{f}, 34$ & a & a & 9 days & - & none & 6 months & - & none & 0.4 \\
\hline \multicolumn{11}{|c|}{ Chronic arthropathy of unknown cause } \\
\hline 147 & $\mathrm{f}, 24$ & $\mathrm{a}$ & $\mathrm{a}$ & $\mathrm{n} / \mathrm{a}$ & - & 7 & $\mathrm{n} / \mathrm{a}$ & - & 7 & 0.6 \\
\hline 124 & f, 38 & A & A & $\mathrm{n} / \mathrm{a}$ & - & $1-3,7$ & $\mathrm{n} / \mathrm{a}$ & - & $1-3,7$ & 0.3 \\
\hline 169 & $\mathrm{~m}, 54$ & A & A & ND & ND & ND & $\mathrm{n} / \mathrm{a}$ & - & none & 0.4 \\
\hline 182 & $\mathrm{f}, 36$ & A & A & $\mathrm{n} / \mathrm{a}$ & - & 7 & $\mathrm{n} / \mathrm{a}$ & - & 7 & 0.9 \\
\hline \multicolumn{11}{|c|}{ B19 exposure with no illness } \\
\hline 156 & $\mathrm{f}, 32$ & none & none & $\exp$ & - & $1-3,7$ & 9 months & - & 7 & 1.1 \\
\hline 022 & $\mathrm{f}, 32$ & none & none & $\exp$ & - & none & 12 months & - & none & 0.3 \\
\hline 178 & f, 36 & none & none & $\exp$ & - & none & 9 months & - & none & 0.8 \\
\hline 132 & $\mathrm{f}, 31$ & none & none & $\exp$ & + & $1-3,4$ & 8 months & - & 7 & 1.6 \\
\hline 036 & $\mathrm{f}, 24$ & none & none & $\exp$ & - & none & 12 months & - & none & 0.4 \\
\hline 133 & $\mathrm{f}, 38$ & none & none & $\exp$ & - & $1-3,7$ & 10 months & - & none & 0.9 \\
\hline 167 & $\mathrm{f}, 36$ & none & none & $\exp$ & - & $1-3,7$ & 10 months & - & none & 0.4 \\
\hline 141 & $\mathrm{f}, 38$ & none & none & $\exp$ & - & $1-3,4,7,8$ & 8.5 months & - & $1-3,7$ & 1.1 \\
\hline 179 & $\mathrm{f}, 32$ & none & none & $\exp$ & - & $1-3,4,7$ & 7 months & - & none & 0.7 \\
\hline 129 & $\mathrm{f}, 37$ & none & none & 17 days & - & $1-3,6,7$ & 9 months & - & $1-3,6,7$ & 0.6 \\
\hline 127 & f, 36 & none & none & 14 days & - & none & 8.5 months & - & none & 0.6 \\
\hline 138 & f, 38 & none & none & $\exp$ & - & $1-3,7$ & 10 months & - & 7 & 0.5 \\
\hline 150 & $\mathrm{f}, 30$ & none & none & $\exp$ & - & 7 & 11 months & - & none & 0.7 \\
\hline 171 & $\mathrm{f}, 33$ & none & none & $\exp$ & - & none & 9 months & - & none & 2.0 \\
\hline 154 & $\mathrm{f}, 40$ & none & none & $\exp$ & - & 7 & 10 months & - & none & 0.7 \\
\hline 140 & $\mathrm{f}, 28$ & none & none & $\exp$ & - & $1-3$ & 10 months & - & none & 0.6 \\
\hline \multicolumn{11}{|c|}{ Healthy controls } \\
\hline 187 & $\mathrm{~m}, 54$ & none & none & $\mathrm{n} / \mathrm{a}$ & - & none & $\mathrm{n} / \mathrm{a}$ & - & none & 0.8 \\
\hline 185 & $\mathrm{~m}, 25$ & none & none & $\mathrm{n} / \mathrm{a}$ & - & none & $\mathrm{n} / \mathrm{a}$ & - & none & 0.2 \\
\hline 139 & $\mathrm{f}, 24$ & none & none & $\mathrm{n} / \mathrm{a}$ & - & 7 & $\mathrm{n} / \mathrm{a}$ & - & none & 1.5 \\
\hline 191 & $\mathrm{~m}, 45$ & none & none & ND & ND & ND & $\mathrm{n} / \mathrm{a}$ & - & 7 & 1.8 \\
\hline 193 & $\mathrm{~m}, 54$ & none & none & ND & ND & ND & $\mathrm{n} / \mathrm{a}$ & - & none & 1.1 \\
\hline 195 & $\mathrm{f}, 34$ & none & none & ND & ND & ND & $\mathrm{n} / \mathrm{a}$ & - & none & 1.0 \\
\hline 189 & $\mathrm{f}, 28$ & none & none & ND & ND & ND & $\mathrm{n} / \mathrm{a}$ & - & none & 0.3 \\
\hline
\end{tabular}

Arthropathy: a, arthralgia (subjective joint pain, only); A, arthritis (joint pain with one or more of the following signs: swelling, heat, tenderness, loss of function). Time: time after onset of symptoms (rash, fever, joint manifestations, etc.) or after exposure (exp) to a known case of erythema infectiosum. PCR: result of direct (nested) PCR for detection of B19 genomic DNA in patient serum (see Materials and methods). ND, not determined; n/a, not available or not applicable.

${ }^{*}$ Presence of NS1-specific IgG bands by immunoblot assay. Numbers refer to NS1-specific bands at the following mol.wts: 1-3, 77-71 kDa; 4, $68 \mathrm{kDa} ; 5,55 \mathrm{kDa} ; 6,48 \mathrm{kDa} ; 7,34 \mathrm{kDa} ; 8,28-25 \mathrm{kDa}$.

${ }^{\dagger}$ Lymphocyte proliferative response to rNS1 in vitro expressed as the stimulation index (SI, see Materials and methods). SIs $>2.0$ were considered positive.

pregnancy with no consequences, and five healthy controls.

\section{Detection of B19-specific DNA by PCR}

Preliminary serum samples collected from the Provin- cial Virology Laboratory archives and follow-up samples (when available) were tested by nested PCR for the presence of B19 genomic DNA (Tables 2 and 3). B19 DNA was detected in early sera of 4 of 13 subjects with confirmed or probable B19 infection for whom samples were available (Table 2). One (subject 
Table 3. Comparative immune response to NS1 in B19 seronegative subjects

\begin{tabular}{|c|c|c|c|c|c|c|c|c|}
\hline \multirow{2}{*}{$\begin{array}{l}\text { Study } \\
\text { no. }\end{array}$} & \multirow{2}{*}{$\begin{array}{l}\text { Sex, age } \\
\text { (years) }\end{array}$} & \multicolumn{3}{|c|}{ Sample 1} & \multicolumn{3}{|c|}{ Sample 2} & \multirow[b]{2}{*}{$\mathrm{NS} 1 \mathrm{SI}^{\dagger}$} \\
\hline & & Time & PCR & NS1 bands* & Time & PCR & NS1 bands* & \\
\hline \multicolumn{9}{|c|}{ B19 exposure with no illness } \\
\hline 145 & f, 31 & $\exp$ & - & 7 & 10 months & - & 7 & 8.2 \\
\hline 159 & f, 29 & $\exp$ & - & none & 9 months & - & none & 0.5 \\
\hline 136 & f, 32 & $\exp$ & - & none & 11 months & - & none & 0.5 \\
\hline 045 & f, 31 & $\exp$ & - & 5 & 9 months & - & 5 & 2.9 \\
\hline \multicolumn{9}{|c|}{ Healthy controls } \\
\hline 184 & f, 53 & $\mathrm{n} / \mathrm{a}$ & - & none & $\mathrm{n} / \mathrm{a}$ & - & none & 0.3 \\
\hline 196 & $\mathrm{~m}, 37$ & ND & ND & ND & $\mathrm{n} / \mathrm{a}$ & - & none & 0.7 \\
\hline 197 & f, 28 & ND & ND & ND & $\mathrm{n} / \mathrm{a}$ & - & none & 0.7 \\
\hline 198 & f, 23 & ND & ND & ND & $\mathrm{n} / \mathrm{a}$ & - & none & 0.5 \\
\hline 194 & $\mathrm{~m}, 34$ & ND & ND & ND & $\mathrm{n} / \mathrm{a}$ & - & none & 0.5 \\
\hline \multicolumn{9}{|c|}{ Chronic arthropathy of unknown cause } \\
\hline 183 & f, 32 & $\mathrm{n} / \mathrm{a}$ & - & 7 & $\mathrm{n} / \mathrm{a}$ & - & none & 3.9 \\
\hline 174 & $\mathrm{~m}, 42$ & $\mathrm{n} / \mathrm{a}$ & - & 7 & $\mathrm{n} / \mathrm{a}$ & - & 7 & 0.9 \\
\hline
\end{tabular}

Footnotes: see Table 2.

149, Table 2) was negative by PCR at 3 days after onset of disease but was found to be positive 9.5 months later. At that time, the patient was still experiencing pain and swelling of her finger joints. B19 DNA was also found in a serum specimen taken shortly after B19 exposure in pregnancy in one subject (132, Table 2) who had experienced no related illness, suggesting subclinical infection. All other samples gave negative results, including those taken from B19 seronegative subjects (Table 3 ).

\section{Detection of NS1-specific antibody by immunoblot assays}

Specific IgG antibodies directed to B19 non-structural (NS1) protein were detected by immunoblot assays employing recombinant NS1 (rNS1) as the target antigen (Fig. 1). Specific antibodies bound at a triplet of bands $(1-3)$ of approximately $71-77 \mathrm{kDa}$ previously identified to be the major band of the rNS1 antigen [18], as determined by the binding of NS1-specific rabbit polyclonal antiserum (A13RD) prepared by immunising rabbits with a C-terminal peptide of NS1 and by the binding of monoclonal anti-His 6 antibody. Five other bands at $c .68,55,48,34$ and $25 \mathrm{kDa}$ (bands $4,5,6,7$ and 8 , respectively) were also recognised by the rabbit positive control serum (Fig. 1) and by some human sera. Individual results are shown in Tables 2 and 3. In those subjects who had confirmed or probable B19 infection, 10 (77\%) of 13 early sera demonstrated NS1-specific IgG while $8(57 \%)$ of 14 serum specimens collected 7.5-12 months after disease onset still had NS1-specific IgG. NS1-specific bands were also observed in acute specimens from the two patients with undiagnosed rash, sera from 3 (75\%) of 4 patients with chronic arthropathy of unknown etiology, and 11 (69\%) of 16 sera collected soon after exposure to EI in pregnancy (Table 2). However, only two healthy seropositive controls had NS1-specific IgG and fol-

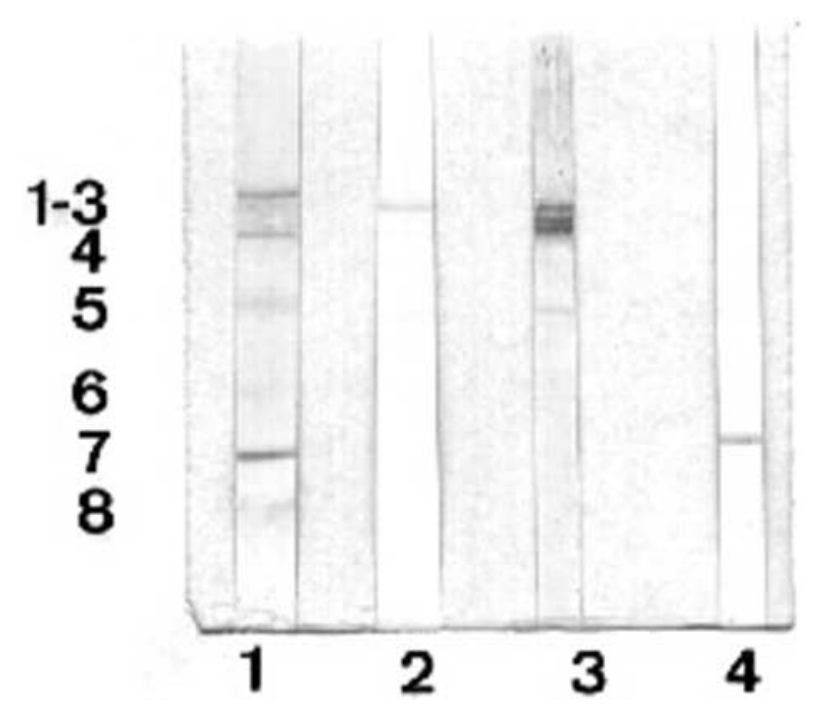

Fig. 1. Immunoblot assay for parvovirus B19 non-structural protein-1 (NS1). Recombinant NS1 protein was transferred to nitrocellulose membranes after SDS-PAGE under reducing conditions and probed with immune sera (see Materials and methods). Lane 1, rabbit anti-NS1 Cterminal peptide (A13RD) showing representative bands (as indicated at the left of the figure) at $77-71 \mathrm{kDa}$ (bands 1-3), $68 \mathrm{kDa}$ (band 4), $55 \mathrm{kDa}$ (band 5), $48 \mathrm{kDa}$ (band 6), $34 \mathrm{kDa}$ (band 7) and 28-25 kDa (band 8) relative to mol.wt markers (not shown); 2, mouse monoclonal anti-His ${ }_{6}$ antibody showing staining of bands $1-3$ and $7 ; 3$, acute phase serum from a B19-infected subject showing staining of bands $1-3$ and 5; 4, serum taken from an otherwise healthy pregnant woman shortly after exposure to a confirmed EI case showing staining of band 7 .

low-up specimens from B19-exposed but otherwise healthy women showed a lower frequency of NS1 antibody (5 of 16 specimens, 31\%) (Table 2).

NS1-specific IgG (minor bands only) were found in two of four VP2 IgG-negative serum specimens from B19 exposed women and the two VP2-specific IgG- 
negative chronic arthropathy patients but not in healthy controls (Table 3).

Major NS1 bands (1-3) were found more commonly in the B19-infected and exposed patient groups. Of the minor NS1 bands, band 7 was recognised most frequently across all patient groups, including three patients who did not have VP2-specific IgG in their serum specimens (Table 3 ). No correlation was found between the presence of VP2-specific IgM, NS1specific IgG, or PCR evidence of B19 genomic DNA in sera in any of the subject groups.

\section{Lymphocyte recognition of parvovirus B19 NS1 protein}

Lymphocyte recognition of parvovirus B19 NS1 was determined by 7-day proliferation assays employing rNS1 as the stimulating antigen at a final concentration of $2 \mu / \mathrm{ml}$ in wells containing peripheral blood mononuclear cells collected at 7.5-12 months after the initial serological investigation (in the case of patient subjects) and in samples collected from healthy controls. Stimulation indices $>2.0$ were considered to indicate a positive response. Individual subject results are shown in Tables 2 and 3. Eight (57\%) of 14 VP2 IgG-positive subjects with either serologically confirmed or probable B19 infection demonstrated positive responses to rNS1 (Table 2). All had experienced acute joint manifestations and four (subjects 153, 157, 126 and 149) had persistent or recurrent arthralgia or arthritis lasting beyond 4 weeks after disease onset. Two patients (149 and 172, Table 2) showing positive cellular responses to NS1 also had persistent B19 capsid-specific IgM (not shown). All subjects with positive cellular responses to rNS1 also had NS1specific antibodies (Table 2) but three patients (153, 175 and 180) showing lymphocyte recognition of NS1 in their late convalescent specimens lacked antibody to NS1 in their sera at that time. Thus, there was no clear correlation between lymphocyte recognition of NS1, presence of NS1-specific IgG, and occurrence of chronic joint manifestations in this group. However, the frequency of lymphocyte recognition of NS1 was significantly higher in subjects who had experienced recent B19 infection (within 12 months of the study) with acute $(p<0.0001)$ or chronic $(p<0.0001)$ joint manifestations in comparison with healthy controls who were VP2 IgG-positive, presumably due to earlier undocumented B19 infection. Interestingly, one B19 IgG-positive subject (171, Table 2) and two VP2 IgGnegative subjects (145 and 45, Table 3 ) with histories of B19 exposure (but no disease) in pregnancy, and one VP2 IgG-negative rheumatology patient (183, Table 3) with recurrent polyarthralgia also demonstrated positive cellular responses to NS1. Two of these patients (145 and 45) demonstrated NS1-specific IgG (minor bands only) in their sera despite having no antibody directed to VP2. However, given the number of subjects studied, the frequency of lymphocyte recognition of NS1 in these groups was not found to be significantly higher than in healthy controls.

\section{Discussion}

Although the association of acute joint manifestations with parvovirus B19 infection is well established, its involvement in the development of chronic arthropathy is still in dispute. Evidence favouring this link comes from studies finding high prevalence of B19 antibodies or confirmed recent B19 infection, or both, in patients with RA [7], JRA [6] or erosive polyarthritis [27]. Other studies have detected B19 DNA (by PCR), antigens (by immunohistochemistry), or replicating virus (by co-cultivation) in bone marrow [12, 14, 15], skin [15], joint tissues [5] and serum [14-16] of patients who subsequently developed chronic arthritis. However, several studies $[9,10,17]$ failed to find significantly higher frequencies of B19 persistence (in any of these tissues) in RA or JRA patients than in patients with osteoarthritis or healthy controls. Although the present study was able to examine peripheral blood only, the sporadic demonstration of B19 sequences by PCR in acute sera was consistent with earlier observations with this type of specimen [17] and probably reflects the timing of the specimen relative to the disease course. B19 DNA was not detected in PBMNC of any of the subjects in this study, despite being detectable in serum specimens. It is possible that the latter outcome may reflect an increase in circulating virus-antibody complexes during the phase of viral clearance. B19-infected cells are also known to be more prevalent in other tissue sites such as the bone marrow or synovial space. Only one patient (149) had detectable B19 in her serum 9.5 months after onset of serologically confirmed B19 infection. She had experienced chronic or relapsing arthralgia and arthritis that continued at the time of follow-up. B19 DNA was also found in one VP2 IgG-positive subject (132) shortly after accidental exposure to a case of EI during pregnancy. As this woman experienced no signs or symptoms of EI and remained healthy throughout the pregnancy, it is possible that the virus may have persisted from an earlier infection [13]. Alternatively, the positive PCR result may have been indicative of subclinical infection. In our opinion, the presence of NS1-specific IgG in this patient's serum after exposure supports the latter interpretation.

Parvovirus non-structural (NS1) protein is known to possess DNA helicase and nickase activities, as well as promoter transactivating properties essential for virus replication in host cells $[1,18]$. Overexpression of NS1 in cells leads to cell cycle arrest and apoptosis [1,28]. NS1 has also been reported to be a transactivator of the promoter for interleukin-6, a pro-inflammatory cytokine [29] made by several cell types known to be adversely affected by B19 infection. Hence, NS1 protein expression could play a role in the ongoing 
inflammation and cell damage associated with persistent B19 infections in non-permissive cells such as synovial membrane cells [30]. Is NS1 expression associated with chronic disease (in particular, arthropathy) following B19 infection? von Poblotzki et al. [20] reported the presence of NS1-specific IgG detected by EIA with recombinant NS1 (rNS1) in three patients with chronic relapsing B19 infection who were followed for 3-18 months. In all three, B19 DNA was detected by PCR or dot blot hybridisation, or both, throughout the study, while detection of IgM directed to capsid protein and NS1 fluctuated according to clinical symptoms. NS1 antibodies appeared to be coincident with predicted cyclical release of NS1 from abortively infected or dying cells. In a separate study, NS1-specific IgG was identified by rNS1 EIA in sera of three patients with severe B19-associated arthritis but not in sera from healthy B19 seropositive and seronegative controls, or acutely B19-infected (B19 IgMpositive) patients [21]. The present study used immunoblot assays to identify NS1-specific IgG in acute or early convalescent specimens of $10(77 \%)$ of 13 patients, with confirmed B19 infection as well as in $2(50 \%)$ of 4 patients with undiagnosed rash illness, and in $11(69 \%)$ of 16 specimens taken at the time of B19 exposure from otherwise healthy pregnant women. The frequencies of detection of NS1 antibodies were not significantly different between these patient groups despite the various clinical outcomes. NS1 antibodies in such B19-exposed (but otherwise healthy) individuals may indicate subclinical infection (or an anamnestic response, or both), while in the symptomatic groups they may be diagnostic of B19 infection. Although NS1-specific IgG was found in follow-up specimens collected from 8 (57\%) of 14 recently infected subjects, all of whom had experienced acute joint manifestations, no clear correlation with progression to chronic arthropathy was found. This does not preclude such an association, as the number of patients studied was small. NS1-specific IgG was also observed in sera of $3(75 \%)$ of 4 subjects with chronic arthropathy of unknown aetiology, and in $5(31 \%)$ of 16 follow-up specimens of B19-exposed subjects, but in only one serum specimen from the healthy control group. Venturoli et al. [31] found equal frequencies of NS1 antibodies in B19-infected patients and healthy seropositive controls, and proposed these antibodies, while likely to be indicative of past infection, may also reflect viral persistence with or without pathological consequences. The observations in the present study concur with this interpretation.

The role of $\mathrm{T}$ cells in either controlling B19 viraemia or in the pathogenesis of B19 disease is presently unknown. Recently, von Poblotzki et al. [24] used recombinant B19 VP1, VP2 and NS1 proteins to examine in-vitro proliferative responses of PBMNC obtained from healthy volunteers. Subjects in their B19 IgG-positive group were assumed to be seropositive as a result of remote undocumented B19 infection.
Lymphocyte proliferation (SI $>2.0$ ) was observed with VP proteins in all $10 \mathrm{~B} 19 \mathrm{IgG}-$ positive subjects, but in none of the six seronegative participants. Low responses to rNS1 were observed in only two seropositive subjects who also had serum antibody to NS1. In the present study, none of the healthy B19-seropositive control subjects demonstrated lymphocyte proliferation to rNS1. However, positive cellular responses were observed in subjects recently (within 8-12 months) infected with or exposed to B19, indicating that lymphocytes capable of recognising NS1 may circulate in the peripheral blood for at least a year. The study also found, in comparison with healthy seropositive controls, a significantly higher frequency of lymphocyte recognition of NS1 in patients who had developed acute and chronic arthropathy. As the study group, by chance, did not include patients who had experienced serologically confirmed B19 infection without onset of joint manifestations, it is difficult to conclude that lymphocyte recognition of NS1 is definitively associated with joint manifestations, and not merely a reflection of recent B19 infection. The observation of NS1 lymphocyte proliferative activity in healthy or asymptomatic (women exposed to EI in pregnancy) and VP2-seronegative subjects calls into question the specificity of the observed response. Although it is possible that E. coli contaminants in the recombinant NS1 preparation may have been stimulatory, this is unlikely to be the case as the frequency of $E$. coli exposure in the general population is high. Hence, if $E$. coli antigens were responsible for the stimulatory effect it should have been observed with equal frequencies in all patient groups. Subjects were defined as being B19seronegative or -seropositive on the basis of antibody directed to recombinant VP2. It is conceivable that some individuals may lack (or have lost) VP2-specific antibodies but may have retained other aspects of B19 immunity including proliferative responses to viral antigens. Further characterisation of the lymphocyte response to B19 proteins will help elucidate whether NS1-reactive lymphocytes are indicators of an initially high viral load (leading to enhanced spread of virus) or persistent B19 infection, both of which may relate to chronic inflammatory tissue damage. With murine parvovirus (MVM-p), NS1 has been shown to be expressed as a complex with B19 DNA on the surface of permissive cells [32]. Hence, if the same proves true for parvovirus B19, surface-bound NS1 could become the target of cytotoxic $\mathrm{T}$ cells. Alternatively, the lymphocyte response may reflect only exposure of the host immune system to NS1 released from dying cells. In the present study NS1-reactive lymphocytes were also detected in peripheral blood of B19-exposed subjects who remained asymptomatic. Hence, these cells, like antibody, may be indicators of recent (clinical or subclinical) B19 infection rather than virus persistence. This remains to be borne out by further study.

We thank Dr Caroline Astell (Department of Biochemistry and 
Molecular Biology, University of British Columbia) for her generous gifts of rNS1 protein and rabbit anti-NS1 sera, Patti Janssen of the Centre for Evaluation Sciences, BC Research Institute for Children's and Women's Health, Vancouver, BC for statistical advice, Dr Janet St Amand (Department of Pathology, University of British Columbia) for advice and helpful discussion concerning PCR and NS1 protein expression and $\mathrm{Dr}$ Aubrey J. Tingle (BC Research Institute for Children's and Women's Health) for helpful discussion.

\section{References}

1. Brown KE. Human parvovirus B19 epidemiology and clinical manifestations. In: Anderson LJ, Young NS (eds) Human parvovirus B19, Monograms in Virology, vol 20. Basel, Karger. 1997: 42-60.

2. Woolf AD, Campion GV, Chishick A et al. Clinical manifestations of human parvovirus B19 in adults. Arch Int Med 1989; 149: $1153-1156$.

3. Gillespie SM, Carter ML, Asch S et al. Occupational risk of human parvovirus B19 infection for school and day-care personnel during an outbreak of erythema infectiosum. JAMA 1990; 263: 2061-2065.

4. Cassinotti P, Bas S, Siegl G, Vischer TL. Association between human parvovirus B19 infection and arthritis. Ann Rheum Dis 1995; 54: 498-500.

5. Takahashi Y, Murai C, Shibata S et al. Human parvovirus B19 as a causative agent for rheumatoid arthritis. PNAS 1998; 95 : 8227-8232.

6. Nocton JJ, Miller LC, Tucker LB, Schaller JG. Human parvovirus B19-associated arthritis in children. $J$ Pediatr 1993; 122: 186-190.

7. Mimori A, Misaki Y, Hachiya T, Ito K, Kano S. Prevalence of antihuman parvovirus B19 antibodies in patients with refractory rheumatoid arthritis and polyarticular juvenile rheumatoid arthritis. Rheumatol Int 1994; 14: 87-90.

8. Hajeer AH, MacGregor AJ, Rigby AS, Ollier WER, Carthy D, Silman AJ. Influence of previous exposure to human parvovirus B19 infection in explaining susceptibility to rheumatoid arthritis: an analysis of disease discordant twin pairs. Ann Rheum Dis 1994; 53: 137-139.

9. Nikkari S, Luukainen R, Mottonen $\mathrm{T}$ et al. Does parvovirus B19 have a role in rheumatoid arthritis? Ann Rheum Dis 1994; 53: $106-111$.

10. Kerr JR, Cartron JP, Curran MD, Moore JE, Elliott JRM, Mollan RAB. A study of the role of parvovirus B19 in rheumatoid arthritis. $\mathrm{Br} J$ Rheumatol 1995; 34: 809-813.

11. Ozawa K, Young N. Characterization of capsid and noncapsid proteins of B19 parvovirus propogated in human erythroid bone marrow cell cultures. J Virol 1987; 61: 2627-2630.

12. Foto F, Saag KG, Scharosch LL, Howard EJ, Naides SJ. Parvovirus B19-specific DNA in bone marrow from B19 arthropathy patients: evidence for B19 persistence. J Infect Dis 1993; 167: 44-48.

13. Sasaki T, Murai C, Muyoi $\mathrm{T}$ et al. Persistent infection of human parvovirus B19 in a normal subject. Lancet 1995; 346: 852 .

14. Toivanen P. Persistence of parvovirus B19 in synovial fluid and bone marrow. Ann Rheum Dis 1995; 54: 597-600.

15. Nikkari S, Lappalainen J, Saario R, Lammintausta K,
Kotilainen P. Detection of parvovirus B19 DNA in skin biopsy, serum, and bone marrow of a patient with fever, rash, and polyarthritis followed by pneumonia, pericardial effusion, and hepatitis. Eur J Clin Microbiol Infect Dis 1996; 15: 954-957.

16. Musiani M, Zerbini M, Gentilomi G, Piazzi M, Gallinella G, Venturoli S. Parvovirus B19 clearance from peripheral blood after acute infection. $J$ Infect Dis 1995; 172: 1360-1363.

17. Soderlund M, von Essen R, Haapasaari J, Kistala U, Kiviluoto O, Hedman K. Persistence of parvovirus B19 DNA in synovial membranes of young patients with and without chronic arthropathy. Lancet 1997; 349: 1063-1065.

18. Astell CR, Luo W, Brunstein J, St Amand J. B19 parvovirus: biochemical and molecular features. In: Anderson LJ, Young NS (eds) Human parvovirus B19, Monograms in Virology, vol 20. Basel, Karger. 1997: 16-41.

19. Liu JM, Green SW, Shimada T, Young NS. A block in fulllength transcript maturation in cells non-permissive for B19 parvovirus. J Virol 1992; 66: 4686-4692.

20. von Poblotzki A, Hemauer A, Gigler A et al. Antibodies to the nonstructural protein of parvovirus B19 in persistently infected patients: implications for pathogenesis. J Infect Dis 1995; 172: 1356-1359.

21. von Poblotzki A, Gigler A, Lang B, Wolf H, Modrow S Antibodies to parvovirus B19 NS1 protein in infected individuals. J Gen Virol 1995; 76: 519-527.

22. Kajigaya S, Momoeda M. Immune response to B19 infection. In: Anderson LJ, Young NS (eds) Human parvovirus B19, Monograms in Virology, vol 20. Basel, Karger. 1997: 120-136.

23. Wagner A, Goronzy JJ, Matteson EL, Weyand CM. Systemic monocyte and T-cell activation in a patient with human parvovirus B19 infection. Mayo Clin Proc 1995; 70: 261-265.

24. von Poblotzki A, Gerdes C, Reischl U, Wolf H, Modrow S. Lymphoproliferative responses after infection with human parvovirus B19. J Virol 1996; 70: 7327-7330.

25. Shade RO, Blundell MC, Cotmore SI, Tattersall P, Astell CR. Nucleotide sequence and genome organization of human parvovirus B19 isolated from the serum of a child during aplastic crisis. J Virol 1986; 58: 921-936.

26. Mitchell LA, Decarie D, Tingle AJ, Zrein M, Lacroix M Identification of immunoreactive regions of rubella E1 and E2 envelope proteins by using synthetic peptides. Virus Res 1993; 29: $33-57$.

27. Tyndall A, Jelk W, Hirsch HH. Parvovirus B19 and erosive polyarthritis. Lancet 1994; 343: 480-481.

28. Moffatt S, Yaegashi N, Tada K, Tanaka N, Sugamura K Human parvovirus B19 nonstructural (NS1) protein induces apoptosis in erythroid lineage cells. J Virol 1998; 72: 3018-3028.

29. Moffatt S, Tanaka N, Tada K et al. A cytotoxic nonstructural protein, NS1, of human parvovirus B19 induces activation of interleukin-6 gene expression. J Virol 1996; 70: 8485-8491.

30. Miki NPH, Chantler JK. Non-permissiveness of synovial membrane cells to human parvovirus B19 in vitro. J Gen Virol 1992; 73: 1559-1562.

31. Venturoli S, Gallinella G, Mararesi E, Gentilomi G, Musiani $\mathrm{M}$, Zerbini M. IgG response to the immunoreactive region of parvovirus B19 nonstructural protein by immunoblot assay with a recombinant antigen. J Infect Dis 1998; 178: 1826-1829.

32. Cotmore SF, Tattersall P. A genome-linked copy of the NS-1 polypeptide is located on the outside of infectious parvovirus particles. J Virol 1989; 63: 3902-3911. 